\title{
Behaviorismo radical e psicanálise: (im)possilidades de articulação conceitual
}

Renato Bastos João ${ }^{1}$

\section{Resumo}

As concepções de evento privado no Behaviorismo Radical (B. R.) e de determinismo psíquico na Psicanálise apontam para uma possível articulação conceitual entre essas perspectivas epistemológicas, já que ambas se referem a fenômenos como estímulos endógenos, sentimentos e pensamentos. Nesse sentido, o presente trabalho se propôs a analisar a (im)possibilidade de se estabelecerem relações conceituais entre a Psicanálise e o B.R. a partir das concepções de evento privado e determinismo psíquico. A metodologia de pesquisa adotada foi a pesquisa bibliográfica, a partir da qual foi realizada uma revisão da literatura acerca dos conceitos e desta discussão aqui proposta. Com este estudo, pode-se sustentar uma articulação conceitual observando-se os conceitos de estímulo interno para B.R. e excitação endógena para a Psicanálise.

Palavras-chave: Behaviorismo Radical. Psicanálise. Eventos privados. Determinismo psíquico. Articulação conceitual.

\section{Introdução}

A expressão Behaviorismo Radical é o título atribuído à proposta filosófica elabora por Skinner $(1953,1989)$ para o estudo do comportamento. Para essa perspectiva epistemológica, o objeto de estudo da Psicologia é o comportamento, compreendido a partir da relação entre o organismo como um todo e o ambiente. Nesse sentido, toda experiência humana é vista como comportamento, sendo que o recorte é externalista e relacional (TOURINHO, 1999).

1 Mestre em Educação (UnB, 2003). Licenciado em Educação Física (UnB, 1999). Graduando em Psicologia (UniCEUB). Docente dos cursos de Educação Física e Pedagogia do Centro Universitário de Brasília - UniCEUB. Email: renatobastosj@yahoo.com.br. 
O enfoque externalista indica que a explicação para o comportamento se volta principalmente para os eventos externos, presentes no ambiente. Este último aspecto é compreendido como o "conjunto de elementos ou eventos que vêm adquirir função de estímulo, passando a constituir o fenômeno comportamental" (TOURINHO, 2001a).

Para o Behaviorismo Radical, os sentimentos, pensamentos, emoções e cognições correspondem a fenômenos que podem e devem ser analisados enquanto comportamento e a partir de uma ciência do comportamento (TOURINHO, 1999). Enquanto que para outras propostas de epistemologia da Psicologia, essas características da experiência humana são elementos constitutivos da subjetividade humana, outra dimensão paralela ou emergente da dimensão corporal-biológica (TEIXEIRA, 2000), e que faz referência à interioridade do sujeito, o Behaviorismo Radical realiza uma crítica a esta perspectiva da subjetividade e busca lidar com esses fenômenos da experiência humana a partir do conceito de evento privado na tentativa de superar empecilhos que a perspectiva subjetivista impõe para o campo da Psicologia (TOURINHO, 1997).

Uma dessas outras propostas de epistemologia para a Psicologia que aponta para uma instância subjetiva e psíquica presente na experiência humana, sendo ela um fator causal do comportamento humano, é a Psicanálise. O objeto de estudo da Psicanálise são os processos psíquicos inconscientes (FILHO, 2000), os quais determinam o comportamento e são de maior frequência no funcionamento psíquico. Esses processos inconscientes estão relacionados a outros aspectos do psiquismo: sexualidade infantil, recalque, resistência, transferência, complexo de Édipo e complexo de castração, entre outros.

As explicações psicanalíticas acerca do comportamento humano têm o foco nos processos psíquicos que ocorrem na pessoa, sendo o recorte internalista diferente do Behaviorismo Radical que, como foi destacado acima, tem um recorte externalista, ou seja, explica o comportamento a partir dos eventos que ocorrem no ambiente.

Todavia, o Behaviorismo Radical assume como objeto de estudo os sentimentos e pensamentos, enquanto comportamento, a partir do conceito de eventos 
privados. As discussões em torno desse conceito tratam de vários aspectos, entre eles, a possibilidade de eventos privados determinarem o comportamento.

É a partir desse último aspecto presente nas discussões acerca dos eventos privados que o presente trabalho se propõe a analisar a (im)possibilidade de se estabelecer relações conceituais entre a Psicanálise e o Behaviorismo Radical, a partir das concepções de evento privado e determinismo psíquico.

\section{Concepções de causa na psicanálise e no behaviorismo radical}

Antes de iniciarmos a discussão a respeito de eventos privados e determinismo psíquico e de apontar a (im) possibilidade de articulação desses conceitos, faz-se necessário apresentarmos as concepções de causa nas duas perspectivas teóricas da Psicologia em discussão neste trabalho.

Conforme esclarece Chiesa (1994), a concepção de causa no Behaviorismo Radical apresenta três aspectos centrais que são os fundamentos da sua explicação sobre o comportamento. O primeiro deles está relacionado à filosofia da ciência de Ernst Mach, a partir da qual Skinner fundamenta sua concepção de causa. Nessa perspectiva, se substitui a ideia de agência causal, forças que causam efeitos, pela ideia de relações funcionais entre acontecimentos. O comportamento é compreendido a partir da descrição de acontecimentos diferentes que tendem a ocorrerem juntos, numa certa ordem (SKINNER, 1953 apud CHIESA, 1994).

O segundo aspecto está relacionado ao foco da influência causal e o reconhecimento da causação múltipla. O significado da expressão causação múltipla é explicita por Skinner ao tratar do comportamento verbal: "(1) a força de uma única resposta pode ser, e usualmente é, função de mais do que uma variável e (2) uma única variável usualmente afeta mais do que uma resposta” (SKINNER, 1957 apud CHIESA, 1994, p. 113). De um modo geral, podemos compreender que o acontecimento de um comportamento se dá a partir da influência de vários fatores ambientais. 
Com relação ao foco da influência causal, o Behaviorismo Radical procura as relações causais na interação do organismo com as várias características do ambiente, ao mesmo tempo em que não desconsidera as influências genéticas e biológicas, de um modo geral, apesar de considerar que elas não são necessárias para uma explicação comportamental (CHIESA, 1994).

O terceiro aspecto do modelo causal de Skinner é sua equiparação com o modelo causal darwinista de seleção de variações. Enquanto o modelo darwinista faz referência à seleção ao longo do tempo de características biológicas particulares de uma espécie, o que está no nível filogenético, o Behaviorismo Radical, aponta também para a seleção de características ao longo do tempo, só que do comportamento, dentre uma ampla faixa de possibilidades disponíveis ao indivíduo, sendo que o foco está no nível ontogenético. Nessa perspectiva, as consequências do comportamento no ambiente é o fator de seleção das variações que podem ser entendidas como uma seleção ambiental (CHIESA, 1994).

Conforme Chiesa (1994), no modelo causal skinneriano se reconhece a presença do gene como unidade biológica dentro da teia causal, na seleção natural. Entretanto, o gene é considerado como mais um elemento acrescentado à rede. Da mesma forma, para o comportamento, é possível identificar unidades biológicas que fazem parte da teia causal, mas como mais um elemento da rede, o que não invalida a seleção como um modelo causal.

Passando à apresentação da concepção de causa na Psicanálise, a primeira coisa a ser dita é que esse tema é muito discutido entre os psicanalistas. Para alguns autores (CALAZANS; SANTOS, 2007; OLIVEIRA, 2002), a concepção de causa ganha mais de uma configuração ao longo da obra de Freud. Todavia, para o presente trabalho, será delineada a perspectiva básica da concepção de causa em psicanálise: o determinismo psíquico.

O sentido desse princípio, num primeiro momento, é o de que no aparelho psíquico nada aconteceria ao acaso, sendo que cada evento psíquico é determinado por outros que o precederam (OLIVEIRA, 2002; BRENNER, 1987). Em vários trechos na sua obra, Freud (1910, 1996, p. 43); expressa claramente seu 
posicionamento, entre eles: "Eu tinha em alto conceito o rigor do determinismo dos processos mentais [...]" "notarão desde logo que o psicanalista se distingue pela rigorosa fé no determinismo da vida mental" (FREUD, 1910, 1996, p. 50); “[...] os senhores acalentam uma fé profundamente arraigada, em acontecimentos psíquicos não-determinados e no livre-arbítrio; que isso, porém, é bastante anticientífico e deve ceder lugar à necessidade de um determinismo cujo princípio se estende à vida mental." (FREUD, 1916, 1996, p. 110).

Outro sentido importante a ser destacado acerca do determinismo psíquico é que Freud (1910, 1996, p. 50) considera a causação múltipla para os eventos psíquicos. Nessa perspectiva, as causas não são lineares, “já que várias delas podem produzir um mesmo efeito" (OLIVEIRA, 2002, p. 26). Essa posição é denominada pelo próprio Freud de sobredeterminação, "cada fenômeno psíquico é determinado, mas pode sê-lo ao mesmo tempo por vários fatores" (LAPLANCHE; PONTALIS apud GOMES, 2005, p. 152).

Além de considerar múltiplas causas para um evento psíquico, o determinismo psíquico abarca, segundo Kusnetzoff (1982, p. 20), o aspecto da ação recíproca, o qual considera que "os efeitos produzidos por várias causas retroagem sobre essas mesmas causas, produzindo-se um condicionamento mútuo ás vezes extremamente complexo".

De acordo com Kusnetzoff (1982), o princípio de ação recíproca é o melhor que se adapta à proposta de causalidade delineada por Freud. Em sua proposta, Freud ( 1996, p. 1916-1917) explica a causalidade a partir da ideia de "séries complementares" em seus textos Conferências XXII e XXIII das Conferências Introdutórias. Essas assim são chamadas pelo fato de descreverem uma sequência interdependente de causas que interatuam entre si.

Nesse sentido, os fatores hereditários e congênitos, as experiências infantis, os fatores atuais ou desencadeantes e os sintomas são séries complementares que mantêm uma influência interdependente e se interatuam configurando a disposição e a dinâmica psíquica de uma pessoa no presente, mas tendo algumas delas origem no passado. 
Outro importante aspecto relacionado à concepção de causalidade na Psicanálise é a questão mente-cérebro. Segundo Gomes (2005, p.151), "a causalidade dos fenômenos psíquicos é coerente com a idéia de que estes têm um substrato natural, neural, mesmo se não se pode explicá-lo em termos neurais". Ao longo de toda a obra de Freud, como esclarece Gomes (2005), é possível identificar o seu entendimento de que os processos psíquicos têm seus fundamentos nos processos neurofisiológicos do cérebro.

Essa posição de Freud coloca sua teoria da mente na categoria das teorias monistas materialistas, mais especificamente, da teoria da identidade psiconeural: o psíquico é o próprio neural (GOMES, 2005).

Entretanto, existem posições diferentes com relação ao entendimento da concepção de mente em Freud. Conforme Candido (2003), podemos conceber a mente ou o aparelho psíquico postulado por Freud como um processo emergente do corpo (orgânico) e de outros fatores externos. Dessa ideia podemos deduzir hipoteticamente que o psíquico tem como um dos fatores causais o substrato neurofisiológico, enquanto parte indissociável do organismo, porém não sendo explicado apenas por ele.

\section{Sobre os eventos privados}

Como foi destacado acima, os problemas da subjetividade são abordados na análise do comportamento (abordagem psicológica fundamentada no Behaviorismo Radical) a partir do conceito de eventos privados. Este é definido por Skinner, conforme nos apresenta Tourinho (1999), "como estímulos e respostas que ocorrem sob a pele do individuo", sendo que a expressão "sob a pele" pode estar fazendo referência ao significado interno ou ao significado inacessível à observação pública.

Sendo o conceito de evento privado o instrumento para lidar com aquilo que é denominado de subjetividade pela maior parte das linhas teóricas da Psicologia, torna-se necessário para a avaliação da eficácia desse conceito confrontá-lo 
com os principais postulados que delimitam epistemologicamente a noção de subjetividade. Para isso se faz necessário esclarecer suas raízes históricas.

Para as perspectivas subjetivistas da Psicologia, o mundo subjetivo é fator determinante do comportamento. Essa posição epistemológica tem suas raízes no dualismo ontológico elaborado por Platão na Grécia antiga (TEIXEIRA, 2000), ganhando presença significativa nos discursos epistemológicos dos séculos XVII e XVIII, com pensadores como Descartes, Bacon, Locke e Hume, os quais se debruçavam sobre a discussão acerca das possibilidades humanas de conhecimento (TOURINHO, 1997).

Como destaca Tourinho, a partir dessa tradição epistemológica, foi delineada uma noção de subjetividade que traz alguns postulados centrais, os quais, apesar de se diferenciarem entre os pensadores, guardam um núcleo principal:

1. cada sujeito possui um mundo interior, pessoal e único; 2. o mundo interior de um é dotado de uma natureza especial, não coincidente com a natureza física dos fenômenos naturais; 3. cada sujeito tem acesso privilegiado aos eventos ou processos de seu mundo interior; 4. o mundo interior de cada um é, em larga medida, um agente que determina o comportamento publicamente observado (TOURINHO, 1997, p. 204).

Dos quatro postulados descritos, o quarto e último é o mais importante para este trabalho e por essa razão será objeto de análise, já que a questão em discussão nos remete a avaliar se os eventos privados têm status de determinação do comportamento. Todavia, alguns pontos relacionados aos outros três postulados, que fazem referência à determinação do comportamento pelos eventos privados, serão tomados para serem discutidos.

Ao analisar se o mundo interno ou os eventos privados, podem ser considerados determinantes do comportamento. Tourinho (1997, p. 207) aponta três contextos diferentes admitidos por Skinner. O primeiro está relacionado à afirmação de Skinner de que os eventos privados fazem parte do ambiente. Partindo dessa proposição, é possível deduzir que, se é no ambiente que se encontram os fatores causais e os eventos privados fazem parte do ambiente, então estes podem ter papel 
na determinação do comportamento. O segundo contexto faz referência ao fato de que o comportamento verbal pode ficar sob controle de estímulos discriminativos privados, como é no caso da dor de dente. E o terceiro, quando um comportamento encoberto está relacionado a um evento público que é subsequente ao primeiro.

Apesar dessas três situações apontadas pelo próprio Skinner, ele mesmo mantém a posição metodológica de que a busca dentro do organismo por uma explicação para a determinação do comportamento não é a melhor estratégia, pois dificulta a identificação das variáveis que estão mais claramente disponíveis no ambiente imediato e na história ambiental do indivíduo (TOURINHO, 1997).

Essa colocação de Skinner nos permite entender que ele mesmo não nega a possibilidade de eventos privados terem status determinante do comportamento, mas sim, que, por uma questão de critério metodológico e epistemológico (a correspondência empírica de toda proposição científica), o foco do Behaviorismo Radical volta-se para o ambiente, onde se encontram as variáveis diretamente observáveis e passiveis de definição empírica e operacional.

Contudo, autores comportamentalistas que já apontaram a posição de Skinner de rejeitar a possibilidade de causação interna do comportamento, ao analisar possíveis inconsistências teórico-conceituais de Skinner, indicam, em sentido contrário, a necessidade de reconhecer a determinação dos eventos privados no comportamento humano (TOURINHO, 1997, p. 207). Entre esses autores encontramos Overskeid (1994 apud TOURINHO, 1997, 2006) em dois momentos diferentes das suas argumentações acerca dessa questão.

No primeiro momento, conforme Tourinho (1997), Overskeid, ao identificar algumas inconsistências na proposta de Skinner acerca dos eventos privados, afirma que causas internas podem ser reconhecidas e devem ser identificadas como causas desencadeadoras do comportamento. Nas próprias palavras do autor, citadas por Tourinho, a seguinte afirmação é apresentada:

Não há razão para se apelar, na explicação do comportamento, a fatores outros que a dotação genética e eventos que mudam o organismo. Mas também não há 
razão para insistir que causas encobertas do comportamento não podem ser tão iniciadoras quanto quaisquer causas (OVERSKEID, 1994, p. 37 apud TOURINHO 1997, p. 207).

Dentre os argumentos de Overskeid que sustentam sua posição com relação à causação dos eventos privados, Tourinho (1997, p. 207) destaca dois: 1) comportamentos verbais podem estar sob o controle de estímulos privados, assim como, comportamentos verbais privados podem ser estímulos discriminativos para comportamento público; 2) "qualquer evento admitido como causa (seja ele interno ou externo ao organismo) implicará uma interrupção na análise da seqüência causal do comportamento, pois a cadeia causal por trás de qualquer evento na natureza é infinita”.

Tourinho (1997) ainda destaca um importante aspecto identificado por Overskeid na concepção de causa da perspectiva skinneriana: a possibilidade de manipulação de uma variável, no sentido de verificar se ela gera mudanças comportamentais, que indicará se essa variável poderá ser considerada causadora do comportamento. A importância de se evidenciar essa característica da perspectiva skinneriana está no fortalecimento do argumento de que é a posição metodológica adotada pelo Behaviorismo Radical o que impede o reconhecimento dos eventos privados como fatores causadores do comportamento.

O segundo momento das argumentações de Oliversked (2006), adotadas para o presente trabalho, faz referência à sua posição de que não há base empírica para sustentar a proposição de que eventos privados não podem ser considerados causadores do comportamento, apenas pelo fato de não poderem ser manipulados e observáveis diretamente.

Ainda neste segundo momento, Oliverskeid (2006) afirma que se o próprio Skinner considerou eventos privados como comportamento, atribuindo a eles a mesma natureza do mundo físico, e que todo comportamento pode ser fator causal para outro comportamento, não há como não reconhecer a potencialidade dos eventos privados enquanto fator causal.

Outra evidência em favor da proposição de que eventos privados podem causar o comportamento é a afirmação de Tourinho (2001b) de que, ao contrário 
da posição de Skinner de considerar os eventos privados como subproduto das contingências, estes devem ser considerados como parte da contingência que está relacionada à determinação de comportamentos públicos, pois têm status de comportamento. Como exemplo de uma situação que tem os eventos privados como parte de contingências, Tourinho (2001b, p. 176) cita o caso da resolução de problemas, "onde se tem uma cadeia de eventos que se encerra com um comportamento público, mas que tem como um de seus elos outro comportamento que pode ser privado", como é nesse caso o pensar.

Além das questões que giram em torno da determinação do comportamento por eventos privados, outro ponto importante a ser discutido para posteriormente confrontá-lo com a posição psicanalítica é a posição skinneriana acerca da natureza do mundo interno. Enquanto que para a tradição subjetivista dos séculos XVII e XVIII, como nos esclarece Tourinho (1997), o mundo interior tem uma natureza diferente do mundo físico, ou seja, dos fenômenos corporais, para Skinner os eventos públicos e privados, estes últimos relacionados ao mundo interior, não possuem nenhum diferença na sua constituição. Nesse sentido, Skinner (1945 apud TOURINHO, 1997, p. 205) vai afirmar que "[...] a minha dor de dente é simplesmente tão física quanto a minha máquina de escrever, embora não seja pública [...]“; e ainda, posteriormente, coloca que

Uma pequena parte do universo está contida dentro da pele de cada um de nós. Não há razão de ela dever ter uma condição física especial por estar situada dentro desses limites, e eventualmente haveremos de ter uma descrição completa dela, descrição que nos será fornecida pela anatomia e pela Fisiologia (SKINNER, 1974, p. 23).

Essa posição de Skinner atribui aos eventos privados equivalência às condições corporais, isto é, o mundo privado ou interior de cada um corresponde às suas condições corporais.

Todavia, conforme esclarece Tourinho (1999, p. 16), os eventos privados, enquanto estímulo e resposta, devem ser entendidos como constitutivos de relações, o que permite afirmar que nenhuma condição privada é, em si mesma, um estimulo e, da mesma forma, que nenhuma ação do organismo é suficiente para se falar de comportamento privado. 
Essa posição conceitual que os eventos privados ocupam na proposta do Behaviorismo Radical tem como consequência teórica a necessidade de distinguir evento privado enquanto condições corporais (estímulos internos) e enquanto sentimentos e pensamentos (comportamentos privado ou encoberto), sendo que estes últimos têm uma base fisiológica, mas não se resumem a ela, pois envolvem um aprendizado comportamental (comportamentos verbais) (TOURINHO, 2001b, p. 177).

Uma segunda consequência é que os sentimentos e pensamentos (eventos privados) não estabelecem uma relação constitutiva com os eventos fisiológicos, isto é, sentimentos e pensamentos não se confundem com as condições corporais de um indivíduo (TOURINHO, 1999, p. 17).

Como exemplo para elucidação dessa posição teórico conceitual, Tourinho afirma que a ansiedade vivenciada por um indivíduo é compreendida pela análise do comportamento como um evento comportamental que se dá em função da relação entre classes de respostas e o controle discriminativo de um conjunto de estímulos e não pelas alterações fisiológicas, tal como a alteração no batimento cardíaco, presentes no momento em que ocorre o evento comportamental.

Nesse sentido, os eventos privados, enquanto aspectos do repertório comportamental, e as condições corporais são compreendidos como produtos paralelos: o primeiro como produto da história ambiental de um organismo - indivíduo (ontogênese), e o segundo, também como produto da história ambiental de um organismo, mas enquanto membro da espécie (filogênese). Dessa forma, não há uma relação causal entre essas duas instâncias que constituem os ventos comportamentais, "um não se explica pela referência ao outro, mas apenas pela referência à historia comportamental" (TOURINHO, 1999, p. 17).

A diferenciação entre os produtos comportamentais e os produtos anátomo-fisiológicos proposta pelo Behaviorismo Radical permite, como foi indicado acima, a superação de uma visão reducionista que busca explicar o comportamento a partir dos processos biológicos e desconsidera a condição relacional que o organismo estabelece com o ambiente, perspectiva esta defendida pelo Behaviorismo Radical (TOURINHO, 1999, p. 18). 
Todavia, essa posição teórica apresentada até aqui permite levantar a seguinte questão: podemos afirmar que, para o Behaviorismo Radical há uma concepção dualista entre corpo e comportamento? Apesar de encontrarmos uma concepção monista de homem sustentada por Skinner, na qual se considera que o ser humano é apenas físico-corpo, a posição teórica delineada por Tourinho (1999, 2001b) sobre a relação entre evento privado e condições corporais, permite esse questionamento.

Ao mesmo tempo, a discussão acerca da relação entre evento privado e condição corporal, como veremos mais à frente, é um importante ponto para discussão da (im) possibilidade de articulação conceitual entre evento privado e determinismo psíquico.

\section{Determinismo psíquico e aparelho psíquico}

De um modo geral, as explicações causalistas em Freud são relativas aos processos psíquicos inconscientes, em termos de conflitos entre instâncias com diferentes modos de funcionamento e em termos de um suposto desejo inconsciente que se choca com um mecanismo de defesa (GOMES, 2005). Dessa forma, o presente sub-tópico apresentará uma descrição do funcionamento do aparelho psíquico no intuito de analisar, posteriormente, a possível ou impossível articulação conceitual entre eventos privados e determinismo psíquico.

Conforme expõe Nasio (1999), para explicar o funcionamento do psiquismo em Freud, pode-se tomar como referência um esquema básico que é o modelo clássico da circulação do influxo nervoso: o esquema do arco reflexo. O esquema do arco reflexo comporta duas extremidades, a sensível e a motora; na primeira, o sujeito percebe a excitação proveniente de uma injeção de quantidade de energia " $x$ " " $x$ "; na segunda, será liberada a energia recebida numa resposta imediata do corpo; entre as duas extremidades instala-se uma tensão que aparece com a excitação e desaparece com a descarga motora.

O funcionamento psíquico tenta obedecer a esse princípio (o arco reflexo), todavia ele se dá parcialmente, pois a descarga total da tensão não acontece, 
fazendo com que na vida psíquica a tensão nunca se esgote. Esse princípio do psiquismo de redução da tensão, compreendido com uma tendência e nunca como uma realização efetiva, é denominado em psicanálise de Princípio de desprazerprazer (NASIO, 1999).

Para explicar o Princípio de desprazer-prazer e o porquê de o psiquismo sempre estar sob tensão, Nasio (1999) retoma o esquema do arco reflexo substituindo os dois pólos deste pelos dois pólos do aparelho psíquico, estando este imerso no meio composto pela realidade externa. Nesse sentido, a fronteira do aparelho psíquico separa um interior de um exterior que o contém.

Para esquematizar sua explicação, Nasio apresenta uma figura (figura 1, a seguir), a partir da qual vai descrevendo o funcionamento do aparelho psíquico.

Figura 1 - Esquema do arco reflexo aplicado ao funcionamento psíquico.

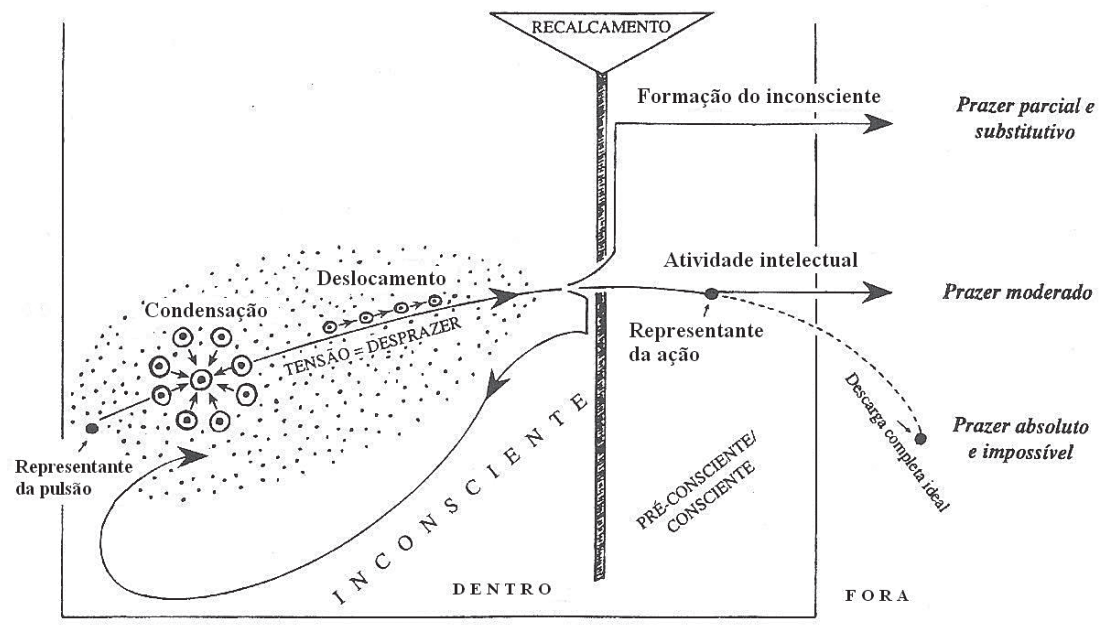

Fonte: Nasio (1999, p. 22)

No polo esquerdo do aparelho psíquico, representado na figura 1, está a extremidade sensitiva que guarda duas características próprias do psiquismo: a excitação é sempre de origem interna, e nunca externa, isso porque, seja uma excitação vinda de uma fonte externa (fatores ambientais) ou de uma fonte orgânica (fatores intrínsecos), cria-se uma marca psíquica, “à maneira de um selo impresso 
na cera”, como destaca Nasio (1999, p. 18), ou ainda uma ideia, uma imagem, ou um representante das pulsões.

A segunda característica se refere ao fato de que o representante, depois de carregado uma vez, vai se manter permanentemente excitado, de tal forma que o aparelho psíquico permanece constantemente excitado, gerando uma tensão que não poderá ser suprimida, pois se realimenta sem cessar. Essa tensão, mantida por uma estimulação ininterrupta e denominada de desprazer, é sentida dolorosamente pelo sujeito, que busca em vão descarregá-la. Dessa forma, o aparelho psíquico se encontra num estado de desprazer efetivo e incontornável e, por outro lado, apresenta-se hipoteticamente, um estado de prazer absoluto, que ocorreria se o aparelho pudesse descarregar toda a energia e eliminar a tensão.

Porém, de acordo com Nasio (1999), a atividade mental humana é alimentada por essa tensão desprazerosa, o que leva a psicanálise a compreender que tensão e desprazer são sinônimos de vida.

Retomando a sua explicação, Nasio (1999) vai apontar três razões que justificam a presença de uma tensão constante no aparelho psíquico. A primeira se refere à característica de que a fonte psíquica da excitação é tão inesgotável que a tensão é constantemente reativada. A segunda razão concerne ao polo direito da figura apresentada acima. $\mathrm{O}$ aparelho psíquico não funciona de maneira a descarregar toda a energia, como o sistema nervoso faz por meio de uma ação motora. Seu funcionamento se dá de forma que a reação à excitação resulta numa metáfora da ação, numa imagem, num pensamento ou numa fala que represente a ação. Por isso, "no psiquismo toda resposta é inevitavelmente metafórica, e a descarga inevitavelmente parcial" (NASIO, 1999, p. 20).

$\mathrm{Na}$ figura que apresenta o esquema proposto por Nasio (1999), podem ser identificado nos dois polos os dois aspectos do funcionamento psíquico descritos até aqui: no polo esquerdo o representante psíquico da pulsão (excitação pulsional contínua) e no polo direito o representante psíquico de uma ação. Essa configuração evidencia a razão de o aparelho psíquico permanecer sob uma tensão constante: enquanto no polo esquerdo o afluxo das excitações é constante e excessivo, 
no direito há apenas um simulacro de resposta (resposta virtual) que implica uma descarga parcial.

A terceira razão e a mais importante que explica por que o psiquismo está sempre submetido a uma tensão é o que Freud denominou de recalcamento. Todavia, antes de apresentar a definição de recalcamento, é necessário esclarecer, como o faz Nasio (1999), que existe uma rede de outros representantes que se encontram entre os dois polos do aparelho psíquico e que configura a sua dinâmica. Ao circular do polo esquerdo para o direito, da excitação para a descarga, a energia atravessa essa rede de representações.

Estando o recalcamento representado por uma barra (figura 1), que separa o esquema proposto em duas partes, a rede intermediária é dividida em dois grupos de representantes. O primeiro grupo majoritário, situado à esquerda da barra, é constituído de representantes carregados de energia e se conectam de uma maneira específica, que formam um caminho mais rápido para tentar chegar à descarga, por meio da condensação (um único representante) ou do deslocamento (passando de um representante para o outro) (Nasio, 1999).

O segundo é constituído por outros representantes da rede, situado no polo direito da barra, que também estão carregados de energia e buscam descarregá-la, mas de uma forma lenta e controlada. Essa situação entre os dois grupos conduz a um conflito, pois o primeiro grupo quer de imediato o prazer de uma descarga total (aqui o prazer é soberano), e o segundo, por reconhecer as exigências da realidade, tende à moderação (a realidade é aqui soberana). O princípio que rege $\mathrm{o}$ primeiro grupo de representantes é o princípio de prazer-desprazer, e o que orienta o segundo grupo é o princípio de realidade (Nasio, 1999).

Conforme Nasio (1999), o primeiro grupo constitui o sistema inconsciente, o qual é composto de representantes pulsionais, denominados por Freud de "representações inconscientes" e também de "representações de coisas", por serem imagens (acústicas, visuais ou tácteis) de coisas ou pedaços de coisas impressas no inconsciente. Essas representações são, principalmente, de natureza visual, sendo a matéria prima que molda os sonhos e, em especial, as fantasias. E ainda, não levam 
em conta as coações da razão, da realidade ou do tempo, atendendo uma única demanda: buscar instantaneamente o prazer absoluto.

O segundo grupo de representantes constitui o sistema pré-consciente/ consciente que também busca o prazer, mas redistribuindo a energia ligada (aquela que investe uma representação consciente) e escoando-a lentamente, conforme o princípio de realidade indica ser possível. A energia ligada é a que sustenta a atividade intelectual intensa. Esses representantes são chamados de representações pré-conscientes e representações conscientes. as primeiras são representações de palavra, as segundas são compostas de uma representação de coisa agregada à representação da palavra que designa essa coisa (NASIO, 1999).

A dinâmica dos representantes nos dois sistemas se dá da seguinte maneira: "a representação de coisa é inconsciente [...] quando não há representação de palavra que se associe a ela e designe a coisa; e é consciente quando, ao contrário, uma representação de palavra vem se ligar a ela” (NASIO, 1999, p. 25).

Apresentado a rede de representantes que existem entre os dois polos do aparelho psíquico, Nasio $(1999$, p. 26) propõe a seguinte definição para o recalcamento: "um adensamento de energia, uma chapa energética que impede a passagem dos conteúdos inconsciente para o pré-consciente”.

Todavia, essa barreira não contém todos os conteúdos inconscientes e recalcados, estes por sua vez irrompem abruptamente na consciência de maneira disfarçada, surpreendendo o sujeito, que não tem consciência da sua origem, vivenciando-o, frequentemente, sob angústia. Essa manifestação deturpada e disfarçada do inconsciente possibilita descarregar uma parte da energia pulsional que lhe proporcionará um prazer parcial e substitutivo, sendo que a outra parte retorna ao inconsciente realimentando a tensão desprazerosa. Esse prazer deve ser entendido como uma descarga, mesmo que esta assuma a forma de um sofrimento.

Com essa descrição do funcionamento do aparelho psíquico podemos compreender três maneiras de descargas proporcionadoras de prazer: 1) uma descarga hipotética, imediata e total, totalmente hipotética, que, se tivesse oportunidade, 
provocaria um prazer absoluto; 2) uma descarga mediata e controlada pela atividade intelectual (pensamento, memória, juízo, atenção etc.), que proporciona um prazer moderado; e 3) uma descarga mediata e parcial, obtida quando a energia e os conteúdos do inconsciente transpõem a barreira do recalcamento (NASIO, 1999, p. 27).

Com o que foi apresentado até aqui acerca do funcionamento psíquico, poderemos realizar a análise proposta para o presente trabalho. Entretanto, é necessário destacar que a proposta de aparelho psíquico de Freud não foi completamente descrita, ficando restrita à primeira proposta, denominada de primeira tópica, não sendo mencionada a segunda proposta, a segunda tópica.

\section{A questão em si: saber da (im)possibilidade de se articular psicanálise e behaviorismo radical a partir das relações conceituais entre evento privado e determinismo psíquico}

Para sabermos da possibilidade ou da impossibilidade de uma articulação conceitual entre as concepções de eventos privados e determinismo psíquico, é necessário analisarmos as diferenças e similaridades entre esses conceitos e entre as concepções de causalidade no Behaviorismo Radical e na Psicanálise.

Com relação às diferenças entre as concepções de causa, um primeiro aspecto a ser destacado é que, enquanto o Behaviorismo Radical adota um modelo de "relações funcionais", a perspectiva da Psicanálise, conforme Chiesa (1994) guarda uma característica do modelo causal mecanicista que é prover elos mediadores internos (aparelho psíquico) entre o comportamento e o contexto em que ele ocorre. Contudo, essa mesma autora reconhece que Freud foi além da explicação a partir dos agentes internos, já que compreendia a importância das variáveis ambientais da história da pessoa, como fatores explicativos de seu comportamento.

Esse último aspecto apontado por Chiesa (1994), sobre o modelo explicativo de Freud, evidencia a consideração à causalidade múltipla presente no modelo psicanalítico, como foi apresentado anteriormente. Esse aspecto, além de ser uma 
similaridade com o modelo do Behaviorismo Radical, articulado com a ideia de ação recíproca, é um indicativo da superação do modelo causal mecanicista na psicanálise.

Uma segunda diferença entre os modelos de causalidade é a perspectiva adotada pelo Behaviorismo Radical da seleção de características comportamentais determinada pelo ambiente. Porém, apesar de o modelo causal psicanalítico não adotar essa perspectiva que enfatiza o impacto do ambiente na formação do repertório comportamental, ele aponta os fatores ambientais (experiências na infância) como constitutivos do aparelho psíquico, o que nos permite questionar se essa diferença pode ser sustentada.

De um modo geral, a causalidade na Psicanálise é uma causalidade psíquica, fundamentada num substrato fisiológico e presente no sujeito, mas também envolvendo fatores externos ao sujeito (ambientais) como determinantes para a constituição psíquica. Já no Behaviorismo Radical, a causalidade é ambiental, considerando-a a partir da relação entre organismos e ambiente. A flexibilização dessa posição pode se dar por meio da discussão acerca da determinação dos eventos privados, contudo a discussão é complexa e necessita de uma análise mais minuciosa.

Partindo das colocações apresentadas por Torinho (1997), sobre os três contextos apontados por Skinner, nos quais os eventos privados têm participação na determinação do comportamento e ainda no caso de resolução de problemas, e por Overskeid $(1994,2006)$, nos dois momentos das suas argumentações apresentados anteriormente, podemos considerar a determinação dos eventos privados (condições corporais e sentimento/pensamentos) no comportamento.

Como foram citadas anteriormente, situações nas quais o comportamento verbal pode estar sob o controle de estímulos privados e comportamentos verbais privados (pensamentos) podem ser estímulos discriminativos para comportamento público, são exemplos da determinação do comportamento por eventos privados.

Na psicanálise, sentimentos e pensamentos são resultantes de um processo caracterizado pelo funcionamento do aparelho psíquico, mais especificamente, 
pela relação entre dois princípios básicos, o de redução da tensão, denominado de princípio de prazer-desprazer, e o princípio de realidade, sendo que o desencadeador desse processo é uma excitação de origem interna. Ou seja, sentimentos e pensamentos são constituídos a partir de um processo psíquico, interno ao sujeito, tendo um substrato orgânico (endógeno).

Ao analisar as posições sobre eventos privados e o funcionamento do aparelho psíquico, no Behaviorismo Radical e na Psicanálise, podemos apontar uma primeira relação: a afirmação de que o comportamento verbal e o comportamento encoberto podem estar sob o controle de estímulos internos, com a explicação psicanalítica de que uma excitação interna desencadeia a dinâmica psíquica. Isso porque estímulo interno e excitação interna podem estar fazendo referência ao mesmo fator.

No mesmo sentido, podemos estabelecer uma segunda relação entre a situação de comportamentos verbais privados (pensamentos) poderem ser estímulos discriminativos para comportamento público e a posição psicanalítica de que o comportamento observável (a fala ou ações em gerais) é determinado por processos psíquicos que resultam nos sentimentos e pensamentos, que por sua fez determinam o comportamento observável.

Todavia, para a sustentação teórica da primeira articulação indicada, é necessário analisar as posições teóricas do Behaviorismo Radical e da Psicanálise sobre, respectivamente, a relação entre sentimento e pensamento (comportamento encoberto) e as condições corporais, e a relação entre aparelho psíquico e corpo (organismo).

No caso do Behaviorismo Radical, as discussões apontam para uma perspectiva de irredutibilidade de sentimentos e pensamentos às condições corporais, sendo defendido, por um lado, um paralelismo entre essas duas instâncias (TOURINHO, 1999), e por outro, uma posição que assume o aparato anátomo-fisiológico como condição para o comportamento e não constitutivo deste (TOURINHO, 2001a). Para essa segunda posição, não são evidenciadas as explicações que esclarecem o que significa a expressão "condição para o comportamento". Entre as duas 
posições, a segunda é mais coerente com a afirmação de que estímulos internos ao organismo podem determinar o comportamento,

Na Psicanálise, duas posições foram apontadas anteriormente: a redução do aparelho psíquico ao substrato neurofisiológico (teoria da identidade psiconeural) (GOMES, 2005) e o aparelho psíquico como emergência do corpo e de fatores externos (CÂNDIDO, 2003). Em ambas as posições se consideram os fatores orgânicos (internos) como causadores do funcionamento psíquico.

Diante dessas posições delineadas, podemos sustentar a primeira articulação indicada, de que estímulo interno e excitação interna podem estar fazendo referencia ao mesmo fator, a partir da posição comportamentalista de que o aparato anátomo-fisiológico é condição para o fenômeno comportamental e da posição psicanalítica com as suas duas perspectivas, já que ambas reconhecem a determinação psíquica a partir de uma fonte interna e endógena (processos orgânicos).

Com relação à sustentação teórica da segunda relação indicada, encontramos alguns impedimentos. Para o Behaviorismo Radical, os eventos privados/ comportamentos encobertos (pensamento e sentimentos) são produtos de contingências ambientais/sociais, pois só a partir do contato com a comunidade verbal é que o indivíduo pode discriminar condições corporais como indicativas de sentimentos como dor, depressão, amor etc., e o pensar, enquanto comportamento verbal privado, é constituído a partir de contingências dispostas pela comunidade verbal (TOURINHO, 2001b).

Para a Psicanálise, pensamentos e sentimentos não são produtos apenas de contingências ambientais/sociais, mas, primordialmente, de processos psíquicos que caracterizam o funcionamento do aparelho psíquico.

Dessa forma, com relação à sustentação teórica da segunda relação indicada, o enfoque de cada uma das teorias discutidas aqui, uma externalista e 
outra internalista, apresentam-se como fator determinante para a impossibilidade de uma articulação conceitual.

\section{Considerações finais}

Com o que pôde ser realizado até aqui, chegamos à conclusão de que a articulação conceitual entre eventos privados e determinismo psíquico pode ser sustentada por uma possível equivalência entre estímulos internos e excitação interna como fatores orgânicos causais do comportamento e do funcionamento psíquico. Já com respeito à segunda relação proposta e analisada, a articulação conceitual não é possível.

O caráter de possibilidade atribuído à primeira proposta de articulação conceitual se deve ao necessário aprofundamento sobre as considerações do Behaviorismo Radical a respeito de estímulos internos (eventos internos) serem causadores de comportamento, já que esse tema é polêmico e desde sua primeira apresentação traz confusões conceituais que até hoje não foram superadas dentro da análise do comportamento (TOURINHO, 1997, 2001b).

Da mesma forma, se faz necessário um maior esclarecimento acerca do conceito de excitação orgânica e os conceitos subsequentes de libido e pulsão, os quais se mostram vagos e sem um correspondente empírico (NYE, 2002).

O esforço aqui realizado se deve à sustentação da posição epistemológica de que temos apenas um mundo perceptível aos órgãos do sentido que aparelham o organismo de todos os seres humanos, o que impõe a necessidade da elaboração de um sistema teórico que possa dar unidade a esse mundo, que no caso do campo de conhecimento da Psicologia se encontra fragmentado. Todavia, as diferenças conceituais estão determinadas por diferenças epistemológicas e metodológicas severas que só poderiam ser superadas a partir da reformulação de princípios epistemológicos e lógicos que acompanham a filosofia e a ciência desde seus primórdios. 


\section{Radical behaviorism and psychoanalysis: (im)possibilites of conceptual articulation}

\section{Abstract}

The concepts of private event in Radical Behaviorism (R.B.) and psychic determinism in psychoanalysis point to a possible conceptual articulation between these epistemological perspectives, both are related to phenomena such as endogenous stimuli, feelings and thoughts. In this sense, this study proposes to analyze the (im)possibility of establishing conceptual relations between psychoanalysis and $\mathrm{BR}$, using the conceptions of private event and psychic determinism. The research methodology used was a bibliographical research from which was held to review the literature about the concepts and this discussion here proposed. It can be sustained from this study a conceptual articulation from the concepts of internal stimulus for R.B. and endogenous excitement for the psychoanalysis.

Keywords: Radical Behaviorism. Psychoanalysis. Private events. Psychic determinism. Conceptual articulation.

\section{Referências}

BRENNER, C. Noções básicas de psicanálise: introdução à psicologia psicanalítica. Rio de Janeiro: Imago, 1987.

CÂNDIDO, C. L. Freud: um monista mentalista? Psicologia: teoria e pesquisa, Brasília, v. 19, n. 2, p. 127-133, 2003.

CHIESA, M. Behaviorismo Radical: a filosofia e a ciência. Brasília: E Celeiro; IBAC 1994.

FREUD, S. Cinco lições de psicanálise. In: Edição standart brasileira das obras psicológicas completas de Sigmund Freud. Rio de Janeiro: Imago, 1996. p. 17-65, v. 11 .

FREUD, S. Conferências introdutórias sobre psicanálise: parte III. In: Edição standart brasileira das obras psicológicas completas de Sigmund Freud. Rio de Janeiro: Imago, 1996. p. 361-378, v. 16. 
FREUD, S. Premissas e técnica de interpretação. In: Edição standart brasileira das obras psicológicas completas de Sigmund Freud. Rio de Janeiro: Imago, 1996. p. 105-116, v. 11.

GOMES, G. O problema mente-cérebro em Freud. Psicologia: teoria e pesquisa, Brasília, v. 21, n. 2, p. 149-155, 2005.

KUSNETZOFF, J. C. Introdução à psicopatologia psicanalítica. Rio de Janeiro: Nova Fronteira, 1982.

NASIO, J. D. O prazer de ler Freud. Rio de Janeiro: J. Zahar, 1999.

NYE, R. D. Três psicologias: ideias de Freud, Skinner e Rogers. São Paulo: Pioneira Thomson Learning, 2002.

OLIVEIRA, F. C. M. de. Determinismo e indeterminismo nos primeiros textos de Freud. Pulsional Revista de Psicanálise, São Paulo, ano 15, n. 155, p. 20-27, 2002.

OVERSKEID, G. Why behave? The problem of initiating causes and the goals of prediction and control. The psychological record, [S.1.], n. 56, p. 323-340, 2006.

PACHECO FILHO, R. A. O método de Freud para produzir conhecimento: revolução na investigação dos fenômenos psíquicos? In: PACHECO FILHO, R. A.; COELHO JUNIOR, N.; ROSA, M. D. (Org.). Ciência, pesquisa, representação e realidade em psicanálise. São Paulo: Casa do Psicólogo; EDUC, 2000. p. 235-289.

SKINNER, B. F. Ciência e comportamento humano. São Paulo: M. Fontes, 1989.

SKINNER, B. F. Sobre o behaviorismo. São Paulo: Cultrix, 1974.

TEIXEIRA, J. de F. Mente, cérebro e cognição. Petrópolis: Vozes, 2000.

TOURINHO, E. Z. Evento privado: função e limites do conceito. Psicologia: teoria e pesquisa, Brasília, v. 13, n. 2, p. 203-209, 1997.

TOURINHO, E. Z. Evento privado: o que, como e por que estudar. In: KERBAUY, R. R; WIELENSKA, R. C. (Org) Sobre comportamento e cognição: psicologia comportamental e cognitiva: da reflexão teórica à diversidade da aplicação. Santo André: ESETec, 1999. p. 13-25.

TOURINHO, E. Z. Privacidade, comportamento e o conceito de ambiente interno. In: BANACO, R. A. (Org.). Sobre comportamento e cognição: aspectos teóricos, 

Universitas: Ciências da Saúde, Brasília, v. 8, n. 1, p. 111-134, 2010
Renato Bastos João

metodológicos e de formação em análise do comportamento e terapia cognitivista. Santo André: ESETec, 2001a. p. 213-225.

TOURINHO, E. Z. Evento privado em uma ciência do comportamento. In: BANACO, R. A. (Org.) Sobre comportamento e cognição: aspectos teóricos, metodológicos e de formação em análise do comportamento e terapia cognitivista. Santo André: ESETec, 2001b. p. 172-184. 